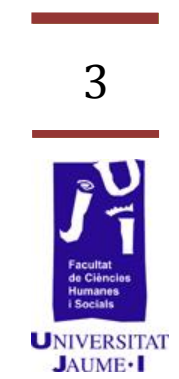

\title{
La Paz Política Una lectura desde la Filosofía para la Paz
}

Ismael Cortés Gómez

Ismaelcortes_@hotmail.com 


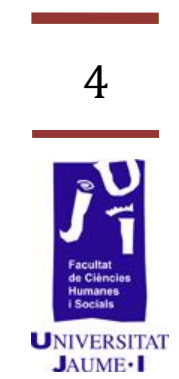

[...] dicen las letras que sin ellas no se podrían sustentar las armas, porque la guerra también tiene sus leyes y está sujeta a ellas, y que las leyes caen debajo de lo que son letras y letrados (Cervantes Saavedra, 1970: 314). 
I. Resumen

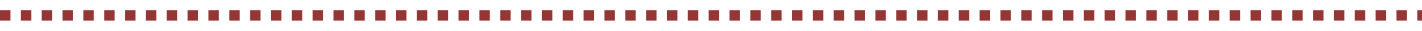

La idea de «paz política» es una propuesta que elabora la International Peace Academy ${ }^{1}$, en el período de la Guerra Fría, como alternativa a la idea hegemónica de «paz armada». La finalidad de la paz armada es evitar la guerra entre dos países, disuadiendo al enemigo de un posible ataque mediante la acumulación y sofisticación tecnológica de material bélico. Entre los años 60 y 90 del siglo XX, ésta fue la estrategia empleada y promovida por las dos superpotencias mundiales, EE. UU. y la URSS, alimentada por la llamada "Guerra de las Galaxias" o "Conquista del Espacio".

Ante este escenario surge la necesidad de adoptar una nueva visión de la paz que supere las concepciones de seguridad militaristas; lo cual conduce a la International Peace Academy a elaborar el concepto de «paz política», lanzando una nueva propuesta que vincula la paz con temas de justicia y derechos humanos. En la actualidad, los Estudios de Paz profundizan en la perspectiva de la «paz política» y elaboran nuevos modelos de seguridad ciudadana, analizando los conflictos en relación a cuestiones de gobernanza, legitimidad democrática, inclusión social o equidad económica.

Palabras clave: paz política, filosofía para la paz, empoderamiento pacifista, democracia, ética comunicativa, reconocimiento.

\section{Introducción}

En el marco de las investigaciones de la Cátedra UNESCO de Filosofía para la Paz, donde realicé el Máster Internacional en Estudios de Paz, Conflictos y Desarrollo ${ }^{2}$, y donde actualmente desarrollo mi investigación de Doctorado, en este artículo me propongo clarificar el concepto de «paz política».

La tesis que defiendo en este artículo es que la Investigación para la Paz necesita potenciar, como estrategia metodológica, el diálogo con las iniciativas pacíficas que llevan a cabo los colectivos sociales que luchan por el reconocimiento de su dignidad política, cultural y económica; en tanto considero que la «paz» es esencialmente una categoría normativa que persigue la ampliación de derechos y libertades ciudadanas.

A continuación desarrollo esta idea en tres puntos: el primer punto está dedicado a explorar la génesis de los conceptos elaborados por Johan Galtung, "(paz positiva», "violencia estructural» y "violencia cultural», en tanto que representan conceptos fundamentales de la

\footnotetext{
${ }^{1}$ Desde 2008 la International Peace Academy pasó a llamarse International Peace Institute.

${ }^{2}$ En este artículo desarrollo algunos de los argumentos más relevantes con los que defendí las conclusiones de mi Tesis de Máster, titulada, La Filosofía para la Paz ante la Teoría Social del Reconocimiento: un diálogo en clave humanista, dirigida por los doctores Fabricio Forastelli y $\mathrm{M}$ a del Carmen Lara Nieto, leída el 27 de Septiembre en la Facultad de Ciencias Humanas y Sociales de la Universitat Jaume I de Castellón.
} 
Investigación para la Paz. En el segundo punto presento el «giro epistemológico » en el que trabajan la Cátedra UNESCO de Filosofía para la Paz (Universitat Jaume I, Castellón) y el Instituto de la Paz y los Conflictos (Universidad de Granada), en base a los conceptos de " (alteridad» y "responsabilidad», haciendo una re-lectura de la ética de Husserl y Lévinas. Finalmente, en el tercer punto reconstruyo el debate que mantienen Habermas, Honneth y Fraser en torno a la ética comunicativa y la teoría del reconocimiento, relevando los argumentos que permiten profundizar en el concepto de «paz política».

\section{Objetivos}

En esta disertación intentaré mostrar que la categoría de «paz política» constituye un marco de análisis complejo, que nos insta a investigar los modos de interacción entre los valores/discursos que orientan la acción colectiva e individual en el mundo de la vida y los marcos jurídicos que provocan sufrimiento a los seres humanos, en las formas de: desigualdad, discriminación, explotación o violencia directa.

\section{La paz positiva}

Desde los años 30 a los 60 se había estudiado la paz desde la óptica de la "(paz negativa»: la paz como la ausencia de guerra. El tema de estudio eran los conflictos armados entre Estados y las herramientas metodológicas empleadas eran la matemática estadística y la teoría de juegos. Algunas de las principales revistas eran Bulletin of the Atomic Scientists (años 40) y Research Exchangeon the Prevention of War (años 50).

En los años 60, el fundador del Instituto de Investigación para la Paz de Oslo, Johan Galtung, introduce un importante giro analítico en la Investigación para la Paz. Galtung incorpora a los Estudios de Paz un análisis sociológico que investiga la relación entre las normas sociales institucionalizadas y los patrones culturales. En una entrevista de 1995 realizada por el investigador del Instituto Universitario de Desarrollo Social y Paz (IUDESP), José María Tortosa, Galtung decía respecto a la Investigación para la Paz: «noté que falta la cultura, el contenido, el ethos, el alma... me dedico más a conectar el análisis estructural con el culturalı (Tortosa, 1995: 163).

Este nuevo enfoque permite al investigador noruego dar una definición normativa de la paz, lo que en Estudios de Paz se conoce como «paz positiva». De acuerdo a este concepto, no podemos hablar de una sociedad pacífica si en su seno viven personas que no tienen satisfechas sus necesidades básicas: seguridad, bienestar, identidad y libertad (Galtung, 2003). La «paz positiva» se alza, pues, como alternativa a la «violencia estructural» (o violencia institucionalizada), que daña la 
satisfacción de necesidades humanas básicas como resultado de un orden legal y/o económico de estratificación social.

De esta forma, Galtung complejiza el análisis de la paz y la violencia, poniendo de relieve que la violencia estructural no solo nos aleja de un modelo ideal de sociedad pacífica, sino que se convierte en causa de la violencia directa: ya sea en la forma de insurrecciones de bandas armadas contra el Estado (guerrillas), en la forma de Imperialismo (dominación de un Estado sobre otros) o incluso en las formas de racismo y sexismo.

En 1990, Galtung precisa aún más la sinergia entre las distintas formas de violencia, con la publicación de su artículo "Cultural Violence» en la revista Journal of Peace Research, en el que se refiere a

[...] those aspects of culture, the symbolic sphere of our existence exemplified by religion and ideology, language and art, empirical science and formal science (logic, mathematics)- that can be used to justify or legitimize direct or structural violence $^{3}$ (Galtung, 1990: 291).

El concepto de «(violencia cultural» completa el triángulo de la violencia sistémica (violencia directa, violencia estructural y violencia cultural) y abre un nuevo campo de análisis en la Investigación para la Paz, que pasa a focalizar los discursos que: por un lado, normalizan las diferencias que existen en la jerarquía social respecto del acceso a recursos materiales, intelectuales o de poder; y por otro lado, justifican los comportamientos violentos tanto de instituciones como de sujetos.

En síntesis, de acuerdo a lo expuesto podemos extraer dos conclusiones sobre la «paz positiva»:

1. La primera es que, tal y como dice Martínez Guzmán, «no vivimos en paz aunque no nos matemos directamente o no estemos en guerra» (Martínez Guzmán, 2005: 50-51; Galtung, 2003). El concepto de «paz positiva» permite visibilizar como violencia los procedimientos legales, económicos y culturales que dificultan o impiden a determinados grupos humanos el acceso a bienes, servicios, derechos y libertades básicas.

2. La segunda es que la «paz positiva» permite identificar la «violencia estructural» y la "violencia cultural» como elementos de un mismo sistema que retroalimenta la «violencia directa».

\section{El giro epistemológico en los Estudios de Paz}

En 1996 el filósofo Vicent Martínez Guzmán fundó la Cátedra UNESCO de Filosofía para la Paz y el Máster Universitario Internacional en

\footnotetext{
${ }^{3}$ Aquellos aspectos de la cultura, la esfera simbólica de nuestra existencia -ejemplificada por la religión y la ideología, el lenguaje y el arte, la ciencia empírica y la ciencia formal (lógica, matemática)- que pueden ser utilizados para justificar o legitimar la violencia directa o estructural (traducción propia).
} 
estudios de Paz, Conflictos y Desarrollo, en la Universitat Jaume I de Castellón. Desde entonces, en estrecha colaboración con el Instituto de la Paz y los Conflictos de la Universidad de Granada (IPAZ), la Cátedra UNESCO trabaja en la producción de un giro epistemológico en los Estudios de Paz que pivota en torno a tres ejes: el carácter productivo/creativo de los conflictos, la dimensión política y cultural de la paz y la violencia, y las competencias humanas para hacer las paces.

Desde la perspectiva que introduce el giro epistemológico, el conflicto es consustancial a la especie humana, debido a los diferentes puntos de vista e intereses (tanto individuales como grupales) que conviven en nuestras sociedades complejas. En esta línea de razonamiento, el investigador del IPAZ Francisco Muñoz sostiene que

como contraposición de intereses y/o percepciones, [el conflicto] está siempre presente en todas las sociedades y actividades humanas [...] el carácter positivo o negativo de los conflictos no depende de sí mismos, sino más bien de los medios que son usados cuando los abordamos (Muñoz, 2001: 28).

Inexorablemente, nuestra naturaleza social nos vincula a los demás, cuya colaboración resulta imprescindible para realizar nuestra propia vida; pero, al mismo tiempo, "los otros" limitan nuestra libertad de acción y decisión, representando una «resistencia» a la expansión de nuestro poder (individual o grupal). Esta visión hace que el conflicto sea un $a$ priori de la actividad social y política, o sea, un marco de acción irrebasable; lo cual, nos lleva a pensar la conflictividad en términos del antagonismo constitutivo de los límites de las sociedades plurales y complejas, donde los conflictos se tornan significativos, en tanto constituyen «un orden de discusión política». En este sentido, el conflicto representa la condición de posibilidad de la política.

Esta antropología del conflicto conduce a la Filosofía para la Paz a preguntarse por las capacidades que posee la especie humana para resolver sus conflictos por medios pacíficos. En este sentido, las investigadoras de la Cátedra UNESCO Irene Comins y Sonia París definen la tarea de la Filosofía para la Paz como:

la reconstrucción normativa de nuestras capacidades y competencias para hacer las paces de las diversas maneras en que los seres humanos podemos hacerlas desde las diferentes culturas (Martínez Guzmán, Comins y París, 2011: 337).

Profundizando en el giro intersubjetivo de la fenomenología que inició Lévinas después de la Segunda Guerra Mundial, que otorga supremacía a la ética por sobre la ontología (Lévinas, 2006), la Filosofía para la Paz propone tres competencias fundamentales para pasar de una cultura de violencia a una cultura de paz: la responsabilidad, el diálogo y el reconocimiento. En consecuencia, partiendo de la convicción de que es en el mundo de la vida (Lebenswelt) donde se forman los valores y significados colectivos que otorgan legitimidad a las prácticas institucionalizadas, la reconstrucción de las competencias para la paz 
representa una propuesta de fundamentación ética para las democracias modernas. De esta manera, la reconstrucción de las competencias para hacer las paces contribuye a lo que los investigadores del IPAZ Francisco Muñoz, Mario López y Enrique Sainz definen como empoderamiento pacifista:

mediante el empoderamiento se intenta restituir a las personas lo más característicamente humano: la conciencia de la relación que hay entre sus propias acciones/decisiones y las consecuencias que resultan de las mismas (López, Muñoz y Sainz, 2004: 396).

El objetivo del empoderamiento pacifista es que la ciudadanía tome conciencia de cuáles son sus capacidades para resolver los conflictos por medios pacíficos. Para lo cual, se propone desarrollar estrategias comunicativas y educativas que hagan frente a la instrumentalización de los recursos simbólicos por parte de las élites políticas y económicas, que acaban generando una percepción interesada de la conflictividad humana (López, Muñoz y Sainz, 2004: 398). En palabras de la investigadora del IPAZ Beatriz Molina Rueda: «El empoderamiento pacifista O fortalecimiento social se centra en el poder que las personas y los grupos ejercen sobre sus propias vidas» (Molina Rueda y Muñoz, 2004: 379).

La Filosofía para la Paz interpreta esta idea de «empoderamiento» a partir de una lectura actualizada de la ética fenomenológica de Husserl y Lévinas. Respecto de este enfoque filosófico fenomenológico, Martínez Guzmán define el empoderamiento del siguiente modo: "Tiene el significado de que alguien recupere sus poderes, sus capacidades; tenga la responsabilidad de potenciar sus competencias, se sienta revalorizado o valorado" (Martínez Guzmán, 2005: 133) [cursiva en el original]. En las siguientes líneas explico en qué consiste esta responsabilidad, y cómo se forma la valoración de sí mismo en relación con "los otros".

Ya en 1807, Hegel definía en la Fenomenología del Espíritu (Hegel, 2010) la singular posición que ocupa el ser humano en la Naturaleza, enfatizando que mientras los demás entes se rigen por principios mecánicos de tipo físico-químico, los seres humanos organizan sus vidas de acuerdo a ideas que se materializan en el poder político del Estado (o Espíritu Objetivo que Hegel contrapone al Espíritu Subjetivo). El sistema filosófico hegeliano pone de relieve el carácter socio-político, y por lo tanto dialéctico, de la vida humana; pero al mismo tiempo, su ontología política amenaza con reducir las posibilidades de interacción humana a los límites de la legalidad producida por el poder político, conduciendo a lo que Husserl criticaba en la Crisis de las Ciencias:

la pérdida de la fe [del ser humano] "en sí mismo», en el ser verdadero que le es propio, un ser que no posee ya desde siempre, que no posee desde la mera evidencia del "yo soy", sino que solo tiene y solo puede tener como propio luchando siempre por su verdad, luchando por hacerse a sí mismo verdadero (Husserl, 1991: 13). 
En el primer tercio del siglo $X X$, Husserl reaviva la filosofía fenomenológica, elaborando una filosofía de la conciencia en la que el sujeto no es producto de un sistema histórico-político, sino que él mismo es el origen de la lógica por la que se rige el mundo de la vida, en tanto sujeto constituyente de sentido. Esta posición fundante del sujeto representa «una actitud crítica universal frente a todo lo tradicionalmente dado de antemano, en cualquiera de sus dimensiones» (Husserl, 1991: 145). De acuerdo a esta idea, Husserl plantea la renovación de la cultura como un problema "ético-individual y éticosocial» (Husserl, 2002: 20), que requiere la elaboración de un nuevo «modelo antropológico» que devuelva al ser humano la confianza en sí mismo, "[como] sujeto de voluntad libre, que interviene activamente en el mundo que nos rodea, que constantemente contribuye a configurarlo» (Husserl, 2002: 2).

Según Husserl, gracias a la actividad reflexiva del "yo» sobre su propia experiencia consciente, es que somos capaces de pasar de una "personalidad pre-ética» a una "personalidad ética» (Husserl, 2002: 2830). Por lo tanto, el fundamento de la responsabilidad moral sería: «el yo [que] se valora a sí mismo, en calidad de sujeto de voluntad, como sujeto que quiere justa o injustamente y que actúa justa o injustamente» (Husserl, 2002: 27). Esta idea llevó a Husserl a definir la responsabilidad como el "deber ético de autoconfiguración» (Husserl, 2002: 24), posibilitado por la capacidad de valorar los propios actos y situarse a sí mismo como origen de los resultados de las propias decisiones/acciones (inspectio sui).

Sin embargo, Martínez Guzmán considera que el «paradigma de la autoconciencia» es insuficiente a la hora de explicar tanto la naturaleza como la génesis de la responsabilidad moral. En la Filosofía para la Paz, la instancia que hace posible la responsabilidad moral del "yo» no es el "yoreflexivo», sino el "otro concreto» (Martínez Guzmán, 2010: 17), desde su concreta situación de sufrimiento. En esta línea de argumentación, la Filosofía para la Paz sustituye el "yo reflexivo» por el «nosotros dialógico», por eso habla de una intersubjetividad constituyente o intersubjetividad originaria:

En nuestra investigación retrospectiva a los orígenes del ego, afrontamos un nivel fundacional que precede la individuación autoreflexiva del ego en su forma concreta. Es una fundamentación que conecta el ego con los otros egos anterior a la individuación auto-reflexiva de cualquier ego. El tema de la intersubjetividad da un giro desde una posición YO/OTRO a una cuestión de coconstitución de mónadas ${ }^{4}$ (Martínez Guzmán, Comins y París, 2011: 343).

Conforme a esta interpretación, la responsabilidad no se desarrolla, principalmente, en el movimiento reflexivo de la conciencia sobre sí misma, sino en el mutuo ejercicio de darnos y pedirnos razones por lo

${ }^{4}$ En el sistema filosófico leibniziano, una mónada es una unidad simple y autónoma de entendimiento que, desde su perspectiva, se representa la totalidad del mundo y se coordina intelectivamente con otras mónadas (Audi, 2004: 591). 
que nos hacemos los unos a los otros (accountability) (Martínez Guzmán, 2005: 36-39; Martínez Guzmán, 2010: 14). En esta línea hermenéutica, la Filosofía para la Paz actualiza la ética de Lévinas, una concepción de la ética centrada en el cuerpo y el lenguaje como condicionantes a priori de la intersubjetividad constituyente de la responsabilidad moral, según la cual:

El uno está implicado en el uno-para-el-otro [...] significa la proximidad del Mismo y del Otro, donde la implicación del uno en el otro significa la asignación del uno por el otro. Asignación que es la propia significación de la significación (Lévinas, 2003: 58).

Tal y como reconoce Lévinas en, "Ética como filosofía Primera» (2006), esta relación intersubjetiva no se refiere a la abstracción de las reglas universales de la ley, sino que atiende al más básico derecho a ser y a la legitimidad de este derecho (Lévinas, 2006: 20); legitimidad que se expresa en el movimiento responsable del yo dirigiéndose a la ayuda del otro sufriente, incluso desobedeciendo la ley. En la conferencia, "Reflexiones para nuevos humanismos» (Martínez Guzmán, 2011), Martínez Guzmán realiza un aporte central sobre esta cuestión, al indicar que el punto de partida del Nuevo Humanismo no son los saberes normalizados, sino la «perplejidad» (thaumazein) que produce el reconocimiento del sufrimiento humano, en las formas de explotación, exclusión, pobreza o violencia directa, y los retos éticos que nos abre esta experiencia.

La problemática del "rreconocimiento» constituye, pues, una preocupación central de la Filosofía para la Paz, en tanto que se ocupa de estudiar los modos de conceptuación de sí mismo en relación con los otros; y cómo el modo de verse a sí mismo, con respecto a los demás, ilumina u opaca nuestra responsabilidad frente al sufrimiento del otro (Martínez Guzmán, Comins y París, 2009: 95). Este análisis nos sitúa ante la siguiente pregunta: ¿cómo justifica el ser humano su existencia, o sea, su modo de ser en el mundo, desde un punto de vista ético?

La tarea de reconstrucción de las competencias para hacer las paces es un modo de responder a esta pregunta, ya que la responsabilidad, el diálogo y el reconocimiento representan no solo competencias, sino también valores o fines que orientan nuestra existencia en la búsqueda de la paz. Ahora bien, si admitimos que estos valores definen la paz, en un nivel fundamental, deberíamos admitir también que la indiferencia, la intolerancia y el menosprecio definen de tal modo la violencia. Así que podemos decir que la violencia comienza con la ruptura del diálogo y con la falta de reconocimiento de la propia responsabilidad ante el sufrimiento del otro.

En esta línea de investigación, la Filosofía para la Paz está interesada en el debate que mantienen abierto Jürgen Habermas, Axel Honneth y Nancy Fraser en torno a la «inclusión del Otro». Estos tres autores trabajan en una hermenéutica crítica que evalúa la ley positiva respecto del consenso social que la respalda, y respecto del proceso comunicativo 
sobre el que se asienta el consenso social; contribuyendo a lo que Lévinas definió en una entrevista de 1988 realizada por Jacques Message y Joël Roman como:

La excelencia misma de la democracia cuyo liberalismo básico corresponde al incesante remordimiento profundo de la justicia: legislación siempre inacabada, siempre retomada, legislación abierta a la mejora (Lévinas, 1993: 39).

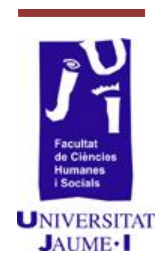

Este «remordimiento liberal», al que hacía referencia Lévinas a finales de los 80, denota simultáneamente la exclusión fáctica del Otro en las democracias liberales y el anhelo de su inclusión. La pregunta flotante aquí es quién (o quiénes) representa(n) la alteridad frente a la identidad, y qué mecanismos ofrece la democracia liberal para hacer efectiva la «inclusión del Otro». A continuación procuro responder estas dos preguntas, reconstruyendo algunos de los argumentos que considero más relevantes del debate abierto entre Habermas, Honneth y Fraser en torno a la categoría de «reconocimiento».

\section{La paz política y la lucha por el reconocimiento}

En su libro titulado, La inclusión del Otro (Habermas, 1999), Jürgen Habermas habla de tres formas de exclusión concurrentes en las actuales democracias liberales: la explotación capitalista, la dominación machista (o el patriarcado) y la discriminación o exclusión racista. Por consiguiente, los grupos víctimas del sistema serían: la clase trabajadora, las mujeres (y el colectivo LGBT) y las "etnias" y/o nacionalidades no europeas (Habermas, 1999: 189-230). Según Habermas, especialmente desde los años 80 , estos grupos se han organizado en movimientos socio-políticos cuyas protestas no se reducen a reivindicaciones de tipo económico, sino que lo que motiva estas luchas son

Las pretensiones no satisfechas históricamente, [por lo tanto] es una lucha por derechos legítimos en la que de nuevo están involucrados actores colectivos que oponen resistencia al desprecio de su propia dignidad (Habermas, 1999: 190).

La finalidad de las "luchas por el reconocimiento» (en reacción al desprecio social) no es generar espacios culturales o políticos diferenciados, sino permitir a los grupos excluidos formar parte de «una comunidad [universal] de sujetos de derecho libres e iguales») (Habermas, 1999: 189); cuyas experiencias y discursos contribuyan tanto a la comprensión que la sociedad tiene sobre sí misma, como a la constitución de un marco jurídico compartido. Según la filósofa feminista Nancy Fraser, esto se debe a que los nuevos movimientos sociales han ampliado el concepto tradicional de «injusticia social», y han comprendido que la subordinación económica está imbricada con fenómenos sociales de exclusión política y con la falta de posibilidades para la autorepresentación cultural (Fraser, 2006: 52; Fraser, 2012: 11). 
Como alternativa a los fenómenos de exclusión y dominación que tienen lugar en las sociedades liberales, debido a la existencia de posiciones asimétricas en las relaciones de poder económicas, políticas y/o culturales, Habermas elabora una teoría de la democracia crítica con los procesos fácticos de validación legislativa:

[EI] Estado de Derecho no puede describirse de modo adecuado, tampoco empíricamente, sin referencia a la dimensión de validez del derecho, y a la fuerza legitimadora que tiene la génesis democrática del derecho (Habermas, 1996: 363).

Con este objetivo, Habermas define cuatro pretensiones de validez con las que se debería comprometer cualquier hablante que quiera participar en un proceso de diálogo: veracidad, inteligibilidad, verdad y corrección normativa (Habermas, 1991: 37; Habermas, 2010: 106). Además, añade a estos cuatro principios el postulado «D» y el principio «U». El postulado «D» dice:

Una norma únicamente puede aspirar a tener validez cuando todas las personas a las que afecta consiguen ponerse de acuerdo en cuanto participantes de un discurso práctico en que dicha norma es válida (Habermas, 1991: 86).

El postulado «D» se complementa con el principio deontológico de universalización «U»:

Toda norma válida debe satisfacer la condición de que puedan ser aceptadas, con libertad por parte de todos los afectados, las consecuencias y efectos colaterales que previsiblemente resulten de su cumplimiento generalizado, para la satisfacción de los intereses de cada uno (Habermas, 1991: 116).

Según Habermas, estos universales procedimentales permiten establecer «el entendimiento lingüístico como mecanismo de coordinación de la acción [social]» (Habermas, 2010: 131), donde cada hablante es un sujeto autónomo que se vincula con otros sujetos autónomos.

Ahora bien, profundizando en el principio «C») de complementariedad del que hablaba Apel en su ética del discurso (Apel, 1991), que «responde a la máxima formal de colaborar en la realización de (U) [la situación ideal de habla], teniendo en cuenta las condiciones situacionales y contingentes") (Apel, 1991: 261), Honneth y Fraser revisan la ética utópica habermasiana y critican su abstraccionismo tanto a la hora de definir el sujeto político como el escenario de acción política. Aunque ambos reconocen la gran aportación de Habermas a la teoría moral y política, al proponer la acción comunicativa como un campo de interacción entre el sistema (mercado y Estado) y el mundo de la vida (espacio socio-cultural donde se generan los significados colectivos), al mismo tiempo problematizan dos premisas fundamentales de su reconstrucción normativa: 
1. La existencia de un sujeto político individual y neutral capaz de identificarse con el interés universal por encima de los intereses particulares que se disputan en un conflicto.

2. La posibilidad de definir un marco racional de acción política que no se vea afectado ni por el conflicto económico ni por la violencia institucional y/o cultural.

A ojos de Fraser, la teoría de la acción comunicativa de Habermas conserva el prejuicio moderno sobre la imparcialidad de la urazón polítican, en la versión actualizada de una comunidad comunicativa ideal. Al hablar de un sujeto político neutral, estamos obviando la desigualdad formal y sustantiva que sufren determinados colectivos sociales por motivos de sexo-género, etnia, nacionalidad o clase social. Por otra parte, al hablar de un sujeto autónomo estamos invisibilizando el carácter social ( $y$, por lo tanto, dialécticamente producido) del sujeto político. Según Nancy Fraser, las luchas por el reconocimiento desenmascaran al sujeto político ideal (o idealizado) y ponen de manifiesto que la sociedad

Tiene una estructura de clases, es decir, que institucionaliza unos mecanismos económicos que niegan de forma sistemática a algunos de sus miembros los medios y las oportunidades que necesitan para participar en la vida social en pie de igualdad con los demás (Fraser, 2006: 52).

De acuerdo a la teoría de la acción política que elaboran Honneth y Fraser, no podemos decir que existe una esfera autónoma de la moralidad, sino que los principios normativos que regulan la praxis política están definidos por sistemas de justicia que se han constituido institucionalmente como resultado de las luchas históricas por el reconocimiento (Honneth, 1997; Fraser, 2006). Este enfoque permite desarrollar una interpretación ética de los conflictos sociales, según la cual, el sujeto político se define como un sujeto colectivo, cuya acción está motivada por pretensiones legítimas de reconocimiento, dando lugar a una dialéctica social que amplía progresivamente el sistema de derechos y libertades.

Este énfasis en las luchas históricas por el reconocimiento, como motor del progreso ético-político de la Humanidad, puede ser puesto en diálogo con el concepto de «paz positiva», aportando criterios normativos para la construcción de sociedades pacíficas. En este sentido, el filósofo de la paz Vicent Martínez Guzmán reconoce que

\footnotetext{
Las rebeliones de los esclavos, la revolución del proletariado, las demandas de los movimientos feministas, indigenistas, étnicos, constituyen luchas por el reconocimiento en el marco de una concepción creativa del conflicto en la que podemos aprender a transformarlo mediante fórmulas no violentas utilizando medios pacíficos de lucha (Martínez Guzmán, 2005: 76).
}

En esta línea de una teoría normativa del reconocimiento, Axel Honneth habla de tres tipos de reconocimiento/menosprecio (Honneth, 1996: 14; 
Honneth, 2010: 24):

1. Reconocimiento de la dignidad corporal, que se hace efectivo mediante la protección de la integridad física y la cobertura de las necesidades materiales básicas: alimentación, vestido, vivienda, trabajo y sanidad. Esta forma de reconocimiento genera en la persona autoconfianza, que se ve dañada por el maltrato (psíquico o físico), la violación sexual, la explotación laboral o la exclusión de servicios sanitarios; es decir, por aquellas agresiones (o privaciones) que restan al sujeto autonomía física.

2. Reconocimiento de la dignidad jurídica y política: este modo de reconocimiento está ligado a la inclusión del sujeto en un sistema universal de derechos, que incluiría: los derechos civiles (que protegen las libertades individuales de las usurpaciones del Estado o de otros individuos), los derechos políticos (que aseguran la participación en los procesos de deliberación política que configuran la opinión pública y/o la voluntad popular) y los derechos sociales (que garantizan una distribución justa y equitativa de la riqueza social). Esta forma de reconocimiento genera en la persona auto-respeto y se ve dañado por la exclusión o desposesión de derechos.

3. Reconocimiento de la dignidad cultural. Esta forma de reconocimiento tiene que ver con la valoración de nuestro estilo de vida, es decir, con el reconocimiento del significado de nuestras acciones en tanto miembros de un determinado colectivo social. Este modo de reconocimiento genera autoestima social (o sea, refuerza nuestro estatus social) y se ve dañado por el desprecio a nuestros valores vitales (mediante el fenómeno de estigmatización), o por la exclusión del colectivo al que pertenecemos de los espacios culturales/intelectuales en los que se producen los significados sociales.

La definición tripartita del reconocimiento que elabora Honneth permite reconstruir las distintas dimensiones de injusticia social, de acuerdo a las reivindicaciones de justicia que emprenden los propios sujetos afectados. Según Axel Honneth, el carácter normativo del reconocimiento está implicado en las luchas sociales que históricamente se han articulado en torno a exigencias de reconocimiento denegado. En palabras de Honneth: «los motivos de rebelión y de resistencia social se constituyen en un espacio de experiencias morales que brotan de la lesión de expectativas profundas de reconocimiento"s (Honneth, 1997: 264).

A este respecto, la filósofa feminista Nancy Fraser sostiene que, en las democracias liberales, las tres formas de menosprecio que señala Honneth no se dan de manera aislada, sino que convergen afectando a determinados colectivos que ocupan una posición social subalterna, verbigracia: las mujeres, la clase trabajadora, los inmigrantes y las etnias no occidentales. La interpretación de Nancy Fraser permite anclar las 
diversas formas de menosprecio a una misma estructura profunda que produce desigualdades de clase y de estatus:

Entonces, no se trata de postular un derecho a la estima social igual para todos, sino de definir, reivindicando la paridad de participación en la interacción social para todos, un campo de la justicia social que implique a la vez redistribución y reconocimiento, clase y estatus (Fraser, 2012: 11).

Según Nancy Fraser (Fraser, 1996: 27-31), el "género", la "etnia" y la nacionalidad son categorías bidimensionales, de carácter culturalvalorativo y político-económico. Por un lado, implican diferencias de estatus provocadas por patrones culturales institucionalizados; y por otro lado, implican diferencias de clase provocadas por la división social del trabajo. Conscientes de esta doble discriminación, «las luchas contra el sexismo ${ }^{5}$ y el racismo, por ejemplo, no pretenden solo transformar el orden del estatus, pues el "género" y la "raza" también implican a la estructura de clases" (Fraser, 2006: 52).

Con este propósito, desde los años 80 acá, se han organizado diversos movimientos sociales que vienen desarrollando estrategias político-programáticas para transformar simultáneamente el orden de la producción simbólica (ligado al reconocimiento) y el orden de la producción económica (ligado a la redistribución). Estas luchas sociales han producido un discurso político que sustituye el concepto clásico de «seguridad territorial», vinculado al poder militar-estatal, por la noción de "seguridad ciudadana», vinculada a la ampliación de derechos y libertades.

\section{Conclusiones}

Para concluir, cabría destacar que en el campo teórico de los Estudios de Paz, y concretamente en la Filosofía para la Paz, el diálogo con las iniciativas pacifistas que se originan en el seno de la sociedad civil supone una estrategia metodológica imprescindible, puesto que como reconoce el investigador del IPAZ, Francisco Muñoz: «una paz fundada exclusivamente en acuerdos políticos y económicos entre gobiernos no podría obtener el apoyo unánime, sincero y perdurable de los pueblos» (Muñoz, 2010: 45).

En esta línea, la Filosofía para la Paz reconstruye las competencias humanas para la paz (responsabilidad, diálogo y reconocimiento), como herramientas críticas al servicio de la ciudadanía para transformar la violencia social en los niveles económico, político y cultural. En palabras del filósofo Vicent Martínez Guzmán:

Se busca la recuperación del mundo de la vida cotidiana donde la coordinación de las relaciones humanas se basa en la comunicación [y el reconocimiento],

\footnotetext{
${ }^{5}$ En la Cátedra UNESCO de Filosofía para la Paz existe una interesante línea de investigación respecto a las luchas sexo-genéricas en el ámbito Hispanoamericano (Forastelli, 2012; Gámez Fuentes, 2010).
} 
frente a la colonización de ese mundo de la vida que producen los sistemas de la economía y el poder (Martínez Guzmán, 2008: 46).

De esta forma, la Filosofía para la Paz asume la responsabilidad que tiene la Universidad como institución encargada de validar científicamente los saberes que educan formalmente a los ciudadanos y ciudadanas de las sociedades modernas. Desde este punto de vista, la misión de los Estudios de Paz es desenmascarar la violencia epistémica que se apoya en la autoridad del saber universitario para justificar prácticas racistas, sexistas, clasistas o imperialistas.

Para llevar a cabo este desenmascaramiento, el diálogo de los investigadores universitarios con los/as protagonistas de los colectivos sociales afectados por estas formas de violencia resulta de vital importancia; puesto que es en los espacios políticos de activismo crítico donde se genera un lenguaje ético que emerge de experiencias concretas de sufrimiento, a partir del cual podemos reconstruir un vocabulario filosófico que fundamente las críticas a un marco normativo que genera explotación, exclusión, dominación o incluso violencia directa de unos grupos humanos sobre otros.

\section{Bibliografía}

APEL, K.o. (1991): Teoría de la Verdad y Ética del Discurso. Paidós. Barcelona.

AUDI, ROBERT (2004): Diccionario Akal de Filosofía. Akal. Madrid.

Cervantes SaAvedra, Miguel de (1970): «Del curioso discurso que hizo Don Quijote de las armas y las letras`, en Don Quijote de La Mancha. Aguilera. Madrid. pp. 313-315.

FORASTELLI, FABRICIO (2012): «Los dilemas de la diferencia desde las luchas de género y sexualidad », en Recerca. Revista de Pensament i Análisi. № 12. $113-128$.

FRASER, NANCY (2012): «lgualdad, identidad y justicia social», en Le Monde Diplomatique. № 201. Julio. Pág. 11.

- (2006): «La justicia social en la era de la política de la identidad: Redistribución, reconocimiento y participación », en Fraser, Nancy y Honneth, Axel: ¿Redistribución o Reconocimiento? Morata/Paideia. Madrid/A Coruña. pp. 17- 88.

- (1996): «Redistribución y reconocimiento: hacia una nueva visión integrada de justicia de género», en Revista Internacional de Filosofía Política. UNAM/UNED. № 8. Pp. 18-40. 
Galtung, Johan (2003): Paz por Medios Pacíficos: Paz y conflicto, desarrollo y civilización. Red Guernika. Guernika.

- (1990): «Cultural Violence», en Journal of Peace Research. Vol. 27, №

3. pp. 291-305.

GÁMEZ FUENTES, MARÍA JosÉ (2010): «La comunicación desde la perspectiva de género", en Irene Comins y Sonia París (ed.), Investigación para la Paz. Estudios Filosóficos. Icaria. Barcelona. pp.145-156.

HABERMAS, JÜRGEN (2010): Teoría de la acción comunicativa. Trotta. Madrid.

- (1996): Facticidad y validez. Sobre el Derecho y el Estado Democrático de Derecho en términos de Teoría Del Discurso. Trotta. Madrid.

— (1999): La inclusión del otro. Paidos. Barcelona.

- (1991): Conciencia moral y acción comunicativa. Península. Barcelona.

HegeL, G.W.F. (2010): La Fenomenología del Espíritu. Abada. Madrid.

HUSSERL, EDMUND (2002): Renovación del hombre y de la cultura. Cinco ensayos. Anthropos/Universidad Autónoma Metropolitana. Barcelona/México.

- (1991): Crisis de las ciencias europeas y la fenomenología trascendental. Crítica. Barcelona.

HONNETH, AXEL (2010): Reconocimiento y menosprecio. Sobre la fundamentación normativa de una teoría social. Katz / CCCB. Buenos Aires / Barcelona.

- (1997): La lucha por el reconocimiento. Por una gramática moral de los conflictos sociales. Crítica. Barcelona.

- (1996): «Reconocimiento y obligaciones morales», en Revista Internacional de Filosofía Política. UNAM/UNED. № 8. Págs. 5-17.

LÉVInas, Emmanuel (2006): «Ética como filosofía primera», A Parte Rei. Revista de Filosofía. № 43. 2-22.

- (2003): De otro modo que ser o más allá de la esencia. Salamanca. Sígueme. 
- (1993): «El otro, utopía y justicia», en Archipiélago: cuadernos de crítica de la cultura. № 12. pp. 35-41.

MARTíneZ GUZMÁN, VICENT (2011): "Reflexiones para nuevos humanismos», Conferencia en el Centro UNESCO ETXEA, 9 de Junio de 2011.

- (2010): «La Filosofía para hacer las Paces: fuentes filosófico-biográficas de la Investigación para la Paz», en Irene Comins y Sonia París (ed.), Investigación para la Paz. Estudios Filosóficos. Icaria. Barcelona. pp. 1124.

- (2008): El papel de la sociedad civil en la construcción de la paz: un estudio introductorio. Icaria. Barcelona.

- (2005): Podemos hacer las paces. Reflexiones éticas tras el 11-S y el 11M. Desclée de Brouwer. Bilbao.

MARTínez GUZMÁN, VICENT, COMINS, IRENE y PARÍS sONIA (2011): "Algunos elementos fenomenológicos para una Filosofía para hacer las Paces», en Investigaciones Fenomenológicas, vol. monográfico 3: Fenomenología y política. pp. 331-348.

Martínez GUZMÁN, VICENT, COMINS, IRENE y PARÍS SONIA (2009): "La nueva agenda de la filosofía para el siglo XXI: los estudios para la paz», en Convergencia, Revista de Ciencias Sociales. UAEM. Núm. Esp. IA. pp. 91114.

Molina rueda, Beatriz y Muñoz, francisco. A. (2004): Manual de Paz y Conflictos. Universidad de Granada. Granada.

MuÑOZ, fRANCISCO. A. (2010): "Una Cultura de Paz compleja y conflictiva. La búsqueda de equilibrios dinámicos», en Revista Paz y Conflictos. Universidad de Granada. № 3. pp. 44-61.

- (2001): "La paz imperfecta ante un universo en conflicto», en Muñoz, Francisco A. (ed.), La paz imperfecta. Universidad de Granada. Granada. pp. 21-66.

MUÑOZ, FRANCISCO. A. et all. (2004): "Empoderamiento», en López Martínez, Mario (dir.): Enciclopedia de Paz y Conflictos. Eirene. Instituto de la Paz y los Conflictos. Universidad de Granada. Granada. pp. 396-398. 
ToRTosa Blasco, José María (1995): «Pasión por la paz: entrevista con Johan Galtung», en Revista Internacional de Filosofía Política. N. 5. pp. 20 153-168. 